\title{
Reliability analysis of solar energy and biogas boiler combination warming system
}

\author{
Jinhui Zhao ${ }^{1}$, Xuwei $\mathrm{Han}^{1, *}$, and Xuexiu $\mathrm{Bai}^{2}$ \\ ${ }^{1}$ School of Mechanical and Power Engineering, Zhengzhou University, Henan, 450001, China \\ ${ }^{2}$ School of Mechanical and Power Engineering, Zhengzhou University, Henan, 450001, China
}

\begin{abstract}
In order to solve the problem of low biogas production caused by low temperature in northern cold area, the solar energy and biogas boiler combination warming system is proposed to raise the temperature of biogas digester. In this paper, under the condition of the optimum area of solar collector, it's obtained that changeable rule of solar energy guarantee rate with month and rule of heating ratio of biogas boiler in the whole year. The solar energy guarantee rate of the system is more than $55.9 \%$, and the combined heating capacity of solar energy and biogas boiler is enough to meet the requirements of annual operation conditions, which is reliable in the northern cold area.
\end{abstract}

\section{Introduction}

With the rapid development of China's aquaculture industry, the discharge of livestock and poultry manure has increased rapidly, and the total amount has exceeded 2.7 billion tons at present [1]. Livestock and poultry manure wastewater is rich in organic substances, which is suitable for biogas production. China is actively developing and utilizing biogas, building more than $4 \times 10^{6}$ biogas digesters and 1580 biogas centralized supply stations [2].

The activity of biogas bacteria is greatly affected by temperature [3], and biogas digesters are mostly built underground, which is greatly affected by ground temperature, while the traditional biogas engineering basically has no heating system [4]. Under natural fermentation conditions, it is difficult for biogas digesters to maintain a high temperature, which will lead to problems such as low gas production rate in winter and biogas digester frost cracking [5-6]. Based on this situation, this paper studies the operation of solar combined biogas boiler heating system in Harbin area, and analyses its reliability.

\section{Solar energy and biogas boiler combination warming system}

\subsection{System schematic diagram}

The system diagram of solar energy combined biogas boiler heating system is shown in Fig. 1. The radius of biogas digester is $3.5 \mathrm{~m}$, the height is $3 \mathrm{~m}$, and the volume is $115.39 \mathrm{~m} 3$. Geothermal pipes are arranged at a spacing of $100 \mathrm{~mm}$ around the inner wall of the pool to

* Corresponding author: hanxuwei@stu.zzu.edu.cn 
heat the biogas slurry in the pool, and $300 \mathrm{~mm}$ thick foamed cement is poured on the wall of the pool.

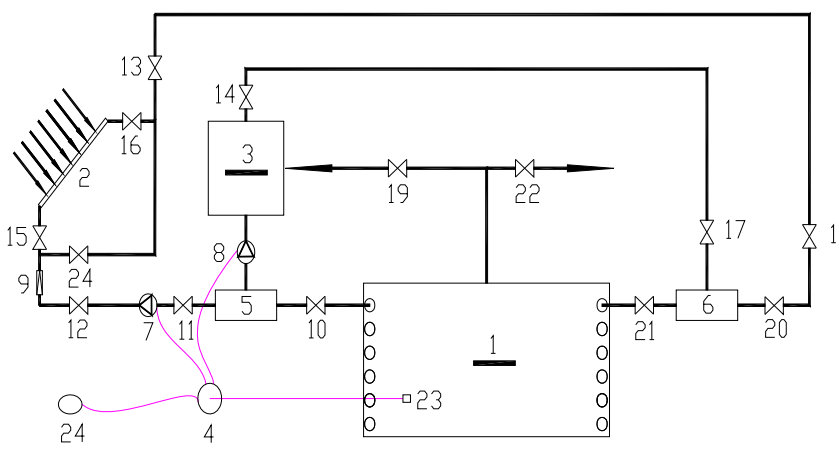

1-biogas digester 2-solar thermal collector 3-biogas boiler 4-water pump controller 5-water knockout drum 6-water collector 7-collector side circulating water pump 8-biogas boiler side circulating water pump 9-fluid flowmeter 10 22-valve 23-temperature sensor 24-radiation sensor

Fig. 1. Schematic drawing of solar energy collector combine biogas boiler to heat up biogas pool system.

\subsection{Working condition flow chart}

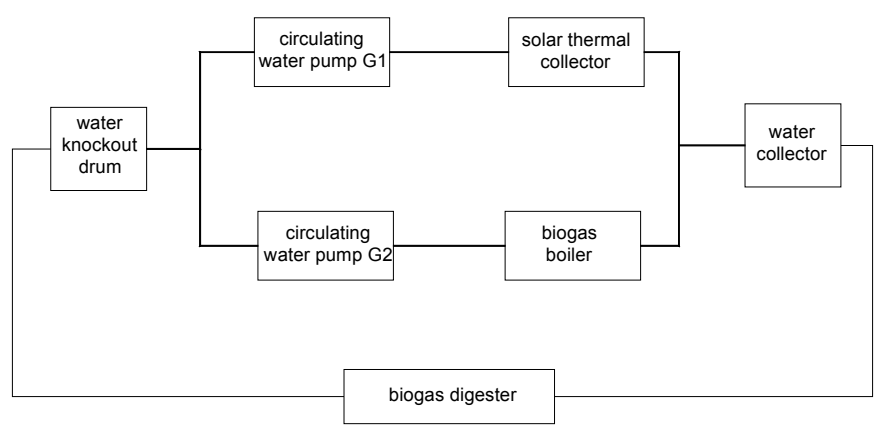

Fig. 2. Process of running situation with solar and biogas boiler.

This system is composed of a heat collector, a biogas boiler, temperature control facilities, biogas digester components, etc. Solar collector system and biogas boiler heating system are connected in parallel, as shown in Fig.2. The optimal fermentation temperature of the biogas digester is set at $35^{\circ} \mathrm{C}$ from January to April, October to December, and $55{ }^{\circ} \mathrm{C}$ from May to September. The circulating pump controls the circulating medium flow of the two branches.

When the amount of solar radiation is greater than the minimum radiation intensity, the radiation intensity sensor controls the solar heating branch to heat the pool, and the excess heat is stored by biogas slurry inside the pool. When the heat collected by the collector can not meet the heat dissipation of biogas, the biogas boiler should be started at the same time, and double heat sources should be used to heat the pool to ensure that the internal temperature of the pool fluctuates within the range of $3^{\circ} \mathrm{C}$. When the solar radiation is less than the minimum radiation intensity, only the heating branch of biogas boiler is turned on, and the solar collector does not work. 


\section{Analysis of the operating conditions of the system in the whole year}

\subsection{Solar energy guarantee rate of the system in the whole year}

The guarantee rate " $f$ " of solar energy system is the percentage of solar energy in the total load of the system [7].

$$
f=\frac{Q_{u}}{L}=\frac{F_{R} A}{L} \int^{\Delta t}\left[I_{T}(\tau \alpha)-U_{L}\left(T_{i}-T_{a}\right)\right] d t
$$

In the above formula

$Q u$-- Useful benefits of collectors, W;

$L$--System load, W;

$F_{R}$--Collector transfer factor;

$A$--Collector area, $\mathrm{m}^{2}$;

$I_{T}$--Total amount of radiation irradiated on the surface of the collector, $\mathrm{J} / \mathrm{m}^{2}$;

$\tau$--Projection coefficient of collector hood system;

$\alpha$--Absorption coefficient of the surface of the absorber plate of the collector;

$U_{L}$--Heat loss coefficient of collector, $\mathrm{W} / \mathrm{m}^{2}$;

$T_{i}$--Inlet temperature of collector fluid, ${ }^{\circ} \mathrm{C}$;

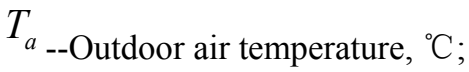

$\Delta t$--The time period in question, $\mathrm{S}$.

The best collector area is $A=100 \mathrm{~m}^{2}$, and the heat load of the system changes with each month. According to the monthly temperature and heat dissipation load of biogas digester in Harbin, the solar energy guarantee rate of the system under the annual operation condition is calculated, and the reliability of the system is analyzed. Detailed calculation results are shown in Table 1.

Table 1. The varied value of assurance ratio by solar energy

\begin{tabular}{|c|c|c|c|c|c|c|}
\hline month & 1 & 2 & 3 & 4 & 5 & 6 \\
\hline $\begin{array}{l}\text { Monthly average } \\
\text { temperature }\left({ }^{\circ} \mathrm{C}\right)\end{array}$ & -18.73 & -14.54 & -2.64 & 7.74 & 14.2 & 20.02 \\
\hline total load $(\mathrm{kW})$ & 10.4 & 9.8 & 7.6 & 5.7 & 6.8 & 6.1 \\
\hline Total monthly load(MJ) & 27855 & 23635 & 20355 & 14670 & 18079 & 15746 \\
\hline $\begin{array}{l}\text { Monthly average daily total } \\
\text { radiation }\left(\mathrm{kJ} /\left(\mathrm{m}^{2} . \mathrm{d}\right)\right)\end{array}$ & 12838 & 15900 & 20458 & 26460 & 30077 & 32760 \\
\hline Collector area $\left(\mathrm{m}^{2}\right)$ & 100 & 100 & 100 & 100 & 100 & 100 \\
\hline Solar energy guarantee rate & 0.559 & 0.727 & 1.026 & 1.255 & 1.289 & 1.354 \\
\hline month & 7 & 8 & 9 & 10 & 11 & 12 \\
\hline Monthly average temperature & 22.85 & 20.95 & 14.71 & 5.16 & -6.62 & -14.83 \\
\hline total load $(\mathrm{kW})$ & 5.75 & 5.97 & 6.70 & 6.04 & 8.12 & 9.81 \\
\hline Total monthly load(MJ) & 15400 & 15990 & 17366 & 16177 & 21748 & 25427 \\
\hline $\begin{array}{l}\text { Monthly average daily total } \\
\text { radiation }\left(\mathrm{kJ} /\left(\mathrm{m}^{2} . \mathrm{d}\right)\right)\end{array}$ & 31025 & 26825 & 21980 & 19830 & 18003 & 13527 \\
\hline Collector area $\left(\mathrm{m}^{2}\right)$ & 100 & 100 & 100 & 100 & 100 & 100 \\
\hline Solar energy guarantee rate & 1.351 & 1.285 & 1.152 & 1.109 & 0.910 & 0.624 \\
\hline
\end{tabular}


In order to more intuitively reflect the change of solar energy guarantee rate with the month under the condition of the selected optimal collector area, it is plotted as Fig.3.

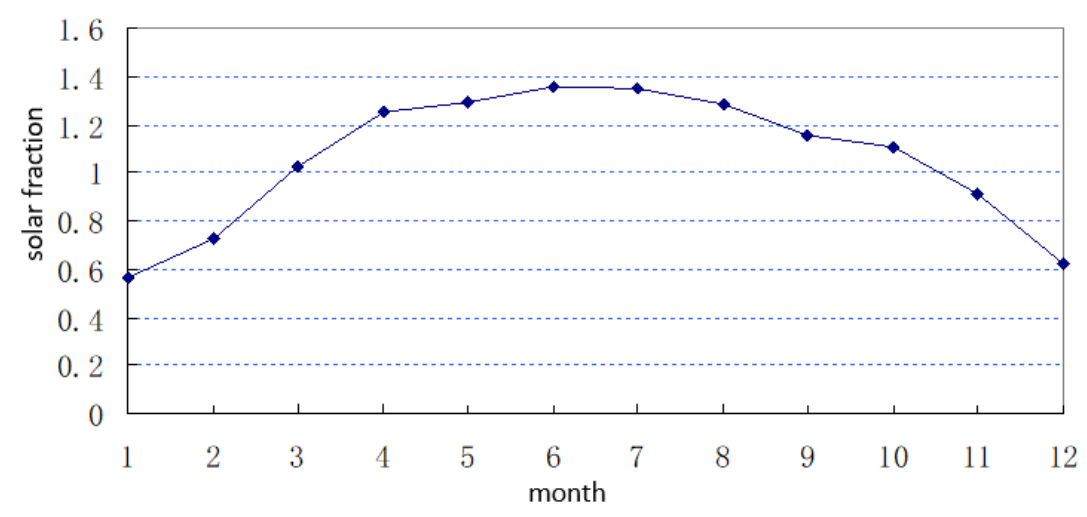

Fig. 3. The varied curve of assurance ratio by solar energy during the all year.

It can be seen from the above figure that the system heats the biogas digester according to solar energy and biogas boiler combination warming system, and the solar energy guarantee rate is above $55.9 \%$. The combined heat supply of solar energy and biogas boiler is enough to meet the requirements of annual operation conditions.

\subsection{Heating ratio of biogas boiler in the whole year}

According to the calculation results in the above section, the relationship between solar energy guarantee rate and months has been obtained. According to the known total heat dissipation load of biogas digesters month by month throughout the year and the formula that $\eta$ biogas boiler $=1-\eta$ heat collector, we can know the heating ratio of biogas boilers throughout the year. The detailed calculation results are shown in the Fig.4.

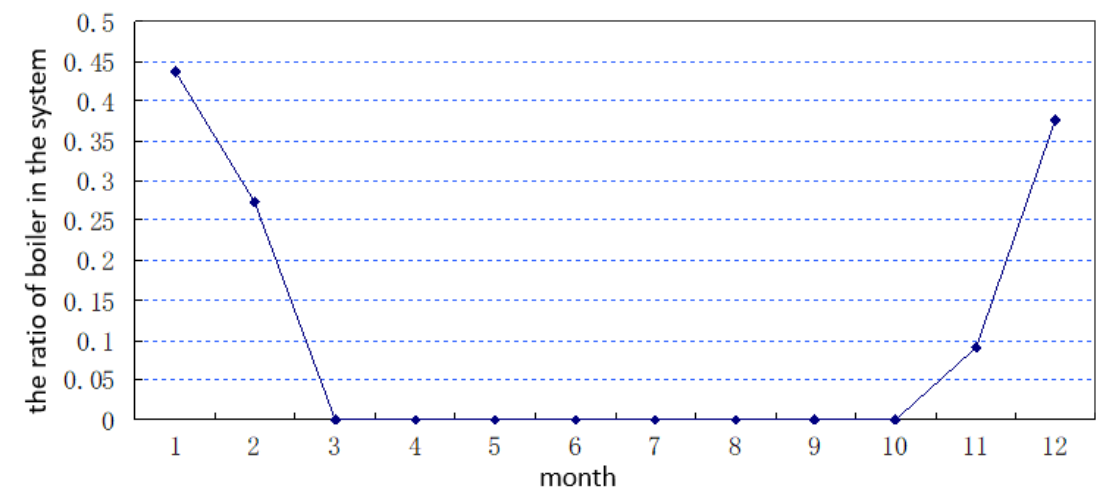

Fig. 4. The calefaction ratio afforded biogas boiler in every month during the all year.

It can be seen from the above figure that from March to October, the solar energy is enough to meet the heat demand for heating the biogas digester, and the solar collector is operated independently, so there is no need for the biogas boiler to supplement the heat. In November, December, January and February, the heat provided by solar heat collection is not enough to maintain the internal temperature of the pool within the set range, so it is 
necessary to start the biogas boiler at the same time and use double heat sources to heat the pool.

\section{Summary}

In this article, the common biogas digester without heating device is greatly affected by ground temperature, so it is difficult to maintain the best fermentation temperature. Especially in cold areas, the temperature in the pool is lowered because of the low temperature in winter, which leads to the low utilization rate of biogas digesters in the north. Therefore, it is proposed to use solar energy and biogas boiler combination warming system to increase the temperature of biogas digesters and keep the temperature of the biogas digesters at the best fermentation temperature.

By analyzing the heating system of solar combined biogas boiler, it is concluded that from March to October, the guarantee rate of solar energy is more than 1, the surplus heat is stored by biogas slurry inside the pool, and temperature control facilities are supplemented to ensure that the temperature inside the pool fluctuates within $3^{\circ} \mathrm{C}$. The system operates in the mode of heating biogas digesters by solar energy alone, and solar energy has surplus heat collection in these months, which can provide residents with domestic hot water in summer. In January, February, November and December, the solar energy guarantee rate is less than 1 . The system heats the biogas digester according to the mode of solar collector combined with biogas boiler. It can be seen from the above table that the solar energy guarantee rate is above $55.9 \%$, and the combined heat supply of solar energy and biogas boiler can meet the requirements.

From the above analysis, it can be seen that the heat of the system in the whole year is enough to meet the requirements, and the system has good reliability when operating in the cold area.

\section{References}

1. Questions and answers on common technologies of livestock manure treatment (I) [J]. Agricultural knowledge, (2016) 09 : 38-40

2. Ouyang, Yuqi, Ni Dachen. Development status and problems in application of biogas energy in China [J]. Energy and energy conservation, (2019) 06: 68-70

3. Bian Yousheng. Waste Treatment and Recycling in Ecological Agriculture. Chemical Industry Press, (2000): $211 \sim 216$

4. Gong Weijie. Recycling technology of agricultural renewable resources (2) [J]. Farmers get rich, (2020) 21: 41

5. WANG Yan-qin, HU Cheng-chang, FU Long-yun, YUAN Chang-bo, YANG Guang, SONG Xiao-zong, BIAN Wen-fan, LIU Ying, YAO Li. Influence of Different Insulation Measures on Rural Digester Temperature and Biogas Production in Winter of Shandong Province[J]. CHINA BIOGAS, (2014),32 04 :57-61.

6. Cui Yanru, technical specification for thermal insulation of household biogas digester and biogas engineering. Jilin Province, Jilin Academy of Agricultural Sciences, (2015)-09-19

7. Fang Rongsheng, Xiang Licheng. Solar energy application technology. China Agricultural machinery press, (1985) :301 305 